Research Paper

\title{
Clinicopathological Characteristics and Prognosis of Ossifying Fibroma in the Jaws of Children: A Retrospective Study
}

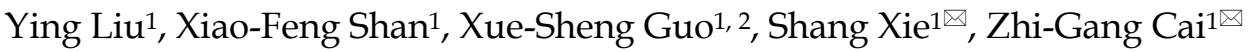 \\ 1. Department of Oral and Maxillofacial Surgery, Peking University School and Hospital of Stomatology, National Engineering Laboratory for Digital and \\ Material Technology of Stomatology, Beijing Key Laboratory of Digital Stomatology, 22\# Zhongguancun South Avenue, Haidian District, Beijing, 100081, \\ China; \\ 2. Department of Stomatology, Capital Medical University Pinggu Teaching Hospital, Beijing 101200, China. \\ $\square$ Corresponding authors: Zhi-Gang Cai, Department of Oral and Maxillofacial Surgery, Peking University School and Hospital of Stomatology, 22\# \\ Zhongguancun South Avenue, Haidian District, Beijing, 100081, China. Email: c2013xs@163.com, Tel: +86 010 82195956, Fax: +86 01062173402 ; or Shang Xie, \\ Department of Oral and Maxillofacial Surgery, Peking University School and Hospital of Stomatology, 22\# Zhongguancun South Avenue, Haidian District, \\ Beijing, 100081, China. Email: xs2013@hsc.pku.edu.cn, Tel: +86 010 82195158, Fax: +86 01062173402. \\ (c) Ivyspring International Publisher. This is an open access article distributed under the terms of the Creative Commons Attribution (CC BY-NC) license \\ (https:// creativecommons.org/licenses/by-nc/4.0/). See http://ivyspring.com/terms for full terms and conditions.
}

Received: 2017.06.21; Accepted: 2017.09.14; Published: 2017.09.30

\begin{abstract}
BACKGROUND: Ossifying fibroma in the jaws is a benign tumor and easily recurs in children, of which the treatment methods and prognosis still remain controversial. In this study, we aimed to review the clinicopathological characteristics, treatment, and prognosis of ossifying fibroma in the jaws of children, and offer recommendations for clinical decision-making.

METHODS: A retrospective study was carried out on patients below the age of 18 years with ossifying fibroma in the jaws. Patients with complete clinical, pathological, and radiological records were included and followed-up.

RESULTS: Sixty-three cases were collected with a preliminary search. After screening, fifty patients were included for general information analysis, of which forty-two patients were included in the recurrence analysis. Twelve patients showed a relapse, with a recurrence rate of $28.6 \%$ (12/42). The recurrence rates in cases with different surgical approaches and different X-ray boundaries were statistically different. Besides, twenty-three patients underwent reconstruction by free tissue grafting and the success rate was $96 \%(22 / 23)$.

CONCLUSIONS: There was significant difference in the recurrence rates among different $X$-ray manifestations and surgical methods. An extended resection and reconstruction with free tissue grafting was a reliable method with a $96 \%$ success rate.
\end{abstract}

Key words: children, ossifying fibroma, treatment, relapse, reconstruction.

\section{Introduction}

Ossifying fibroma is a benign tumor with a good prognosis in adults [1-4] while easily recurs in children [5-10]. Relapses and multiple surgeries could result in facial deformity, sometimes even lead to malignant transformations [11]. Thus, it is important to find out the most appropriate treatment. Till now, the treatment of ossifying fibroma in children still remains controversial $[7,12-16]$. Some scholars believe that ossifying fibroma in children should be treated by radical resection [6, 13, 17-19] because of the aggressive nature of the tumor. However, other scholars suggest that the treatment should be more conservative [3,10,14], considering the growth and development of the children. Both views render decision making difficult. When we scrutinized the studies of ossifying fibroma in children's jaws, we find that the sample sizes are small and the clinical outcomes are generally insufficient [20]. In order to 
offer better clinical decisions, we reviewed the medical record in the Peking University School and Hospital of Stomatology, and analyzed the characteristics, treatment, and prognosis of ossifying fibroma in the jaws of children.

\section{Materials and Methods}

A retrospective case series study was conducted. The potentially eligible patients were from the Peking University School and Hospital of Stomatology, China. Patients who were diagnosed with ossifying fibroma and treated in this institution between January 1990 and May 2016 were included in our study with the criteria of younger than 18 years old. The medical records, X-ray films, and pathology specimens were reviewed. Diagnosis was confirmed by senior maxillofacial, radiology and pathology specialists. The gender, age, anatomical site, radiological features, surgical approach, pathology subtypes, and relapsed history after treatment were also collected. Follow-up data was obtained from the outpatient medical records and follow-up calls.

\section{Included criteria and excluded criteria}

All included cases should have sufficient clinical, radiological, and pathological features that resembled the characteristics of ossifying fibroma. The excluded criteria were the absence of any above information or any case controversies in diagnosis.

\section{Group division}

To better analyze the characteristics of patients, we divided patients into different groups according to ages, imaging, histology and treatments. And the details of classification foundations were as following:

\section{Ages}

According to Nelson's Pediatrics and Convention on the Rights of the Child, patients were divided into 6 groups: infant period (0 1 years), toddler period (1 3 years), pre-school period (3 6 years), school period (6 10 years), early adolescence (10 14 years), and late adolescence (14 18 years) [21, 22].

\section{Imaging}

The margins of the tumors in the X-ray films were grouped as well-defined and poorly-defined [23]. With respect to density, tumors were divided into radiolucent, radiopaque, and a combination of radiolucent and radiopaque $[3,4,24]$.

\section{Histology}

Based on the 2005 World Health Organization Classification of Tumors [25], all cases were divided into three histological subtypes: classic ossifying fibroma, juvenile trabecular ossifying fibroma (JTOF), and juvenile psammomatoid ossifying fibroma (JPOF).

\section{Surgical Methods}

The various surgical approaches were as follows: curettage, local resection, and radical resection. In this study, 'curettage' meant the scaling of a tumor tissue. 'local excision' meant the resection of the whole tumor along the edge of the tumor, whilst 'radical excision' meant the removal of a tumor in a normal bone tissue, $5 \mathrm{~mm}$ outside the boundary $[4,12]$.

\section{Statistical analysis}

The SPSS software 19.0 was used for statistical analysis. The recurrence rates among the different groups were compared. The chi-square test and Spearman correlation analysis were conducted to compare the prognosis of the different groups. A value of $p$ less than 0.05 was considered statistically significant.

\section{Results}

The data of sixty-three patients were collected. Three cases were excluded because of incomplete medical records. Six cases were dropped out for lack of X-ray films or controversial in radiological diagnosis. Besides, four patients were also excluded owing to no specimen or controversial in pathological diagnosis. Finally, fifty patients were included for general information analysis.

Of the fifty patients, five patients only had biopsy and three patients were lost to follow-up, so the eight patients were excluded. At last, forty-two patients were included for recurrence analysis. The flow diagram of included and excluded cases was shown in Figure 1.

\section{Clinical features of the included patients}

There were thirty-four males and sixteen females, giving a sex ratio of 2:1. Ages ranged from one to eighteen years old with a median age of eleven years old. The age distribution of gender difference was showed in Figure 2. Twenty-three cases occurred in the maxilla, twenty-six in the mandible, and one case was a multiple lesion in both jaws. Disease duration ranged from one week to six years. Swelling or an asymptomatic growth of the jaws was the most common chief complaint. Other patients reported nasal congestion, biting discomfort, tinnitus, or slight tenderness. Two were accidentally discovered by a routine X-ray examination. Most of the tumors grew slowly, while two had accelerated growth in the second and sixth month. The number and percentage of each group are shown in Table 1. 


\section{Radiological features}

A computed tomography scan including spiral $\mathrm{CT}$ and cone beam CT was conducted on thirty-seven patients. Thirteen patients had only plain X-ray films in panoramic view or Water's view. Forty-four cases showed a well-demarcated globular mass. The other six cases had poorly defined boundaries. Based on the density of the tumors, nineteen cases were radiolucent, thirteen were radiopaque, whilst eighteen were a combination of radiolucent and radiopaque. Twenty-nine cases had tooth drift, whilst nine cases had slight root absorption.

total number of cases with a discharge diagnosis

of ossifying fibroma $(n=63)$

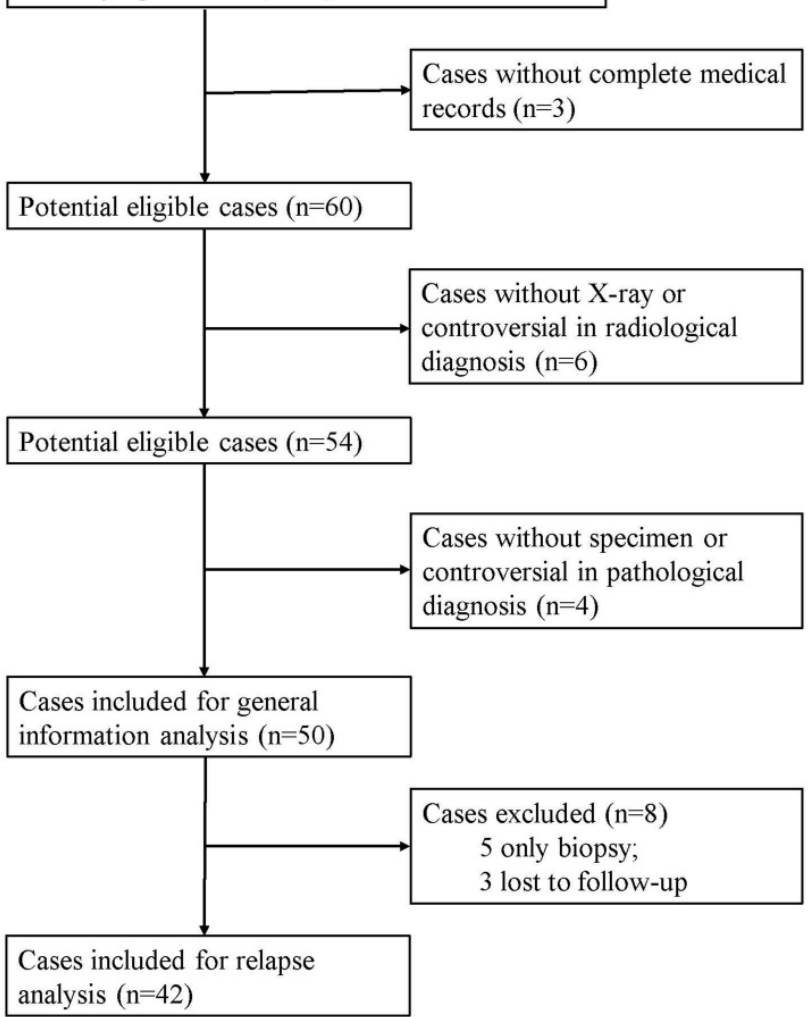

Figure 1. A flow diagram of included and excluded cases.

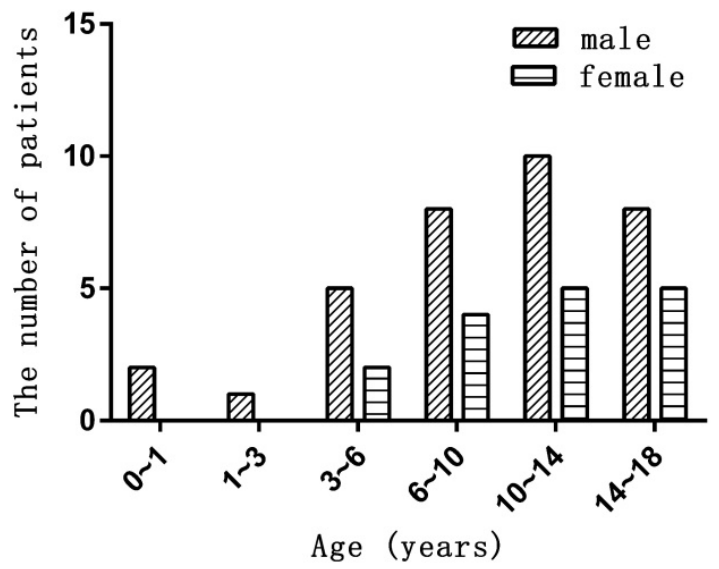

Figure 2. The age distribution in different genders.

\section{Surgical approach and pathology subtypes}

Five patients had a biopsy, eight patients underwent the curettage, and ten received a local resection. Twenty-seven cases had radical resection, including six maxillary subtotal resections, four maxillary total resections, three mandibular en-block osteotomies, and fourteen mandibular segment osteotomies. Eleven patients had once or twice surgeries in other institutions and referred to our hospital. The pathological subtypes of the fifty cases were as follows: twenty-nine, classic ossifying fibroma; twenty-one, juvenile ossifying fibroma $(9$, JPOF; 12, JTOF). Juvenile ossifying fibroma accounted for $42 \%(21 / 50)$ of all kinds of ossifying fibroma.

Table 1. Clinical, radiological and pathological characteristics $(n=50)$

\begin{tabular}{|c|c|c|}
\hline & Number & Percentage (\%) \\
\hline \multicolumn{3}{|l|}{ Sex } \\
\hline Male & 34 & 68 \\
\hline Female & 16 & 32 \\
\hline \multicolumn{3}{|l|}{ Age (y) 1-18 (median 11) } \\
\hline $0 \sim 1$ & 2 & 4 \\
\hline $1 \sim 3$ & 1 & 2 \\
\hline $3 \sim 6$ & 7 & 14 \\
\hline $6 \sim 10$ & 12 & 24 \\
\hline $10 \sim 14$ & 15 & 30 \\
\hline $14 \sim 18$ & 13 & 26 \\
\hline \multicolumn{3}{|l|}{ Position } \\
\hline Maxilla & 23 & 46 \\
\hline Mandible & 26 & 52 \\
\hline Both jaws & 1 & 2 \\
\hline \multicolumn{3}{|l|}{ Radiological features } \\
\hline Well defined margin & 44 & 88 \\
\hline Poorly defined margin & 6 & 12 \\
\hline Radio lucent & 19 & 38 \\
\hline Radio opaque & 13 & 26 \\
\hline Radiolucent \& radiopaque & 18 & 36 \\
\hline Tooth drift & 29 & 58 \\
\hline Tooth resorption & 9 & 18 \\
\hline \multicolumn{3}{|l|}{ Pathology subtype } \\
\hline Classis ossifying fibroma & 29 & 58 \\
\hline JPOF & 9 & 18 \\
\hline JTOF & 12 & 24 \\
\hline \multicolumn{3}{|l|}{ Relapsed lesion } \\
\hline Yes & 11 & 22 \\
\hline No & 39 & 78 \\
\hline
\end{tabular}

The follow-up period ranged from 3 months to 163 months with the median period of thirty months. Twelve cases were relapsed with a recurrence rate of $28.6 \%(12 / 42)$. The relapse time was between the 3rd and 52nd months after surgery. Seventy-five percent $(9 / 12)$ of the cases relapsed within one year.

Of the twelve cases that relapsed, ten repeated surgery, which included two local resections and eight radical resections. The two local resection cases 
were lost to follow-up, whilst for the eight radical resection cases, six had no recurrence and two relapsed. Radical excision was repeated again in these two cases, after which there were no signs of recurrence during the follow-up period and no malignant transformation was found during follow-up period.

\section{Recurrence analysis}

The recurrence rate of lesions with well-defined boundaries was $26.3 \%(10 / 38)$, whilst that of poorly defined boundaries was $50 \%(2 / 4)$. The recurrence rate of curettage was $85.7 \%(6 / 7), 55.6 \%$ (5/9) for local resection, and $3.8 \%(1 / 26)$ for radical resection. The results showed that the different $X$-ray boundaries and surgical methods were statistically different among the groups. However, there were no significant differences in the gender, age, position, radiological density and pathological subtype between the groups. The details are shown in Table 2.

\section{Reconstruction}

In total, twenty-three patients underwent reconstruction with free tissue graft. Sixteen cases were reconstructed with fibula flap graft, four cases with anterolateral thigh flap graft, two cases with iliac flap graft, and one with free rib graft. One anterolateral thigh flap graft of a 6-year-old boy was removed due to vascular crisis. The youngest patients among those with successful reconstruction with different flaps were aged 1 year, 7 years, 10 years, and 13 years. The total success rate was $96 \%(22 / 23)$. For patients, recovering the oral function is important and necessary after operation. In our cases series, both the removable prosthesis and fixed prosthesis (implant) were common methods. Sometimes, the implantation could get absolutely results. In Figure 3, a 17-year-old boy diagnosed of ossifying fibroma underwent segmental resection of mandible. The defect was reconstructed by a fibula flap grafting. Bony union was observed three months after operation. Five years after operation, implantation was applied and a good functional outcome was achieved.

Table 2. Recurrence rates according to different factors $(n=42)$

\begin{tabular}{|c|c|c|c|c|c|}
\hline & Number & Relapse & No relapse & $\begin{array}{l}\text { Recurrence } \\
\text { rate }(\%)\end{array}$ & $\mathrm{P}$ \\
\hline \multicolumn{6}{|l|}{ Sex } \\
\hline Male & 31 & 10 & 21 & 33 & 0.375 \\
\hline Female & 11 & 2 & 9 & 18 & \\
\hline \multicolumn{6}{|l|}{ Age } \\
\hline $0 \sim 1$ & 2 & 1 & 1 & 50 & 0.287 \\
\hline $1 \sim 3$ & 0 & 0 & 0 & - & \\
\hline $3 \sim 6$ & 5 & 2 & 3 & 40 & \\
\hline $6 \sim 10$ & 10 & 5 & 5 & 50 & \\
\hline $10 \sim 14$ & 14 & 2 & 12 & 14 & \\
\hline $14 \sim 18$ & 11 & 2 & 9 & 18 & \\
\hline \multicolumn{6}{|l|}{ Position } \\
\hline Maxilla & 20 & 7 & 13 & 35 & 0.379 \\
\hline Mandible & 22 & 5 & 17 & 23 & \\
\hline \multicolumn{6}{|l|}{ Radiological features } \\
\hline Well defined margin & 38 & 10 & 28 & 26 & 0.000 \\
\hline Poorly defined margin & 4 & 2 & 2 & 50 & \\
\hline Radio lucent & 16 & 5 & 11 & 31 & 0.955 \\
\hline Radio opaque & 11 & 3 & 8 & 27 & \\
\hline Radiolucent \& radiopaque & 15 & 4 & 11 & 27 & \\
\hline \multicolumn{6}{|l|}{ Surgical approach } \\
\hline Curettage & 7 & 6 & 1 & 86 & 0.000 \\
\hline Local resection & 9 & 5 & 4 & 56 & \\
\hline Radical resection & 26 & 1 & 25 & 4 & \\
\hline \multicolumn{6}{|l|}{ Pathology subtypes } \\
\hline Classic ossifying fibroma & 25 & 6 & 19 & 24 & 0.492 \\
\hline JPOF & 8 & 2 & 6 & 25 & \\
\hline JTOF & 9 & 4 & 5 & 44 & \\
\hline \multicolumn{6}{|l|}{ Relapsed lesion } \\
\hline Yes & 9 & 1 & 8 & 11 & 0.247 \\
\hline No & 33 & 11 & 22 & 33 & \\
\hline
\end{tabular}

momatoid ossifying fibroma; JTOF: juvenile trabecula ossifying fibroma.

(1)

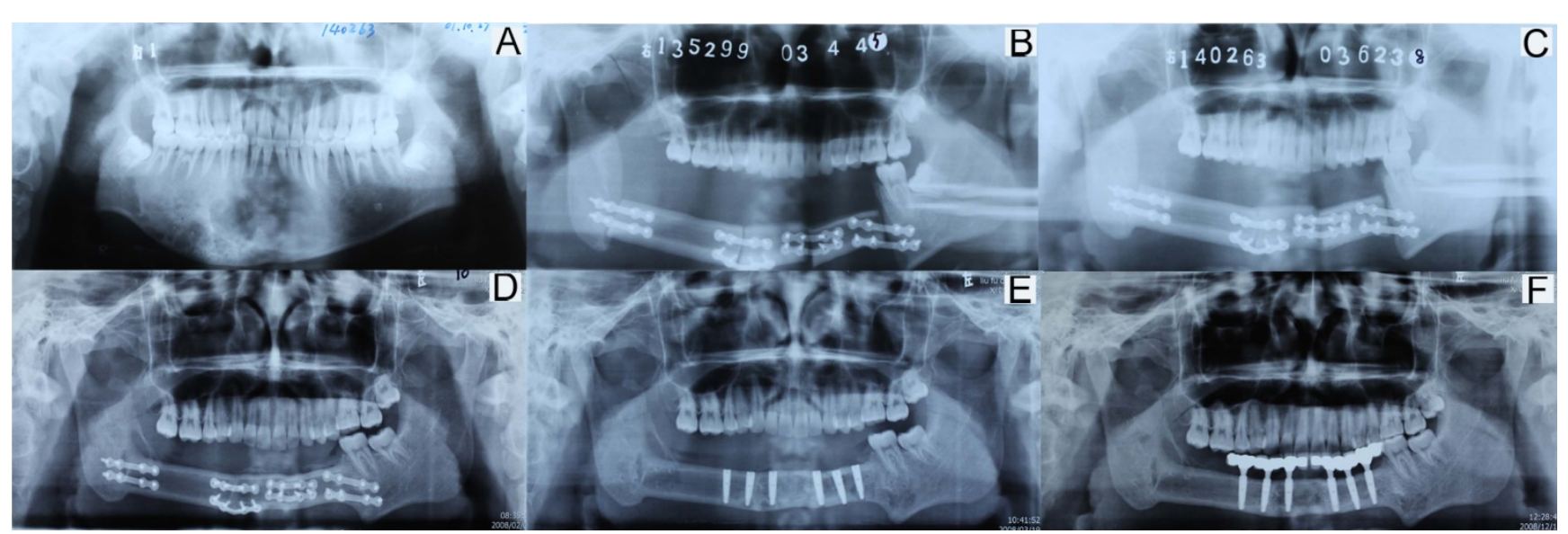

Figure 3. Imaging of reconstruction with a fibular flap graft in a 17-year-old boy. (A: pre-operation; B: one week after operation; C: three months after operation; D: five years after operation, pre-implantation; E: implant placement; F: implant-support prosthesis). 


\section{Discussion}

To our knowledge, this study is the largest sample sizes of children to report with the diagnosis of ossifying fibroma.

In this study, ossifying fibroma showed a male predominance, which is consistent with some previous studies [12, 20, 26]. In contrast, most literatures indicated that ossifying fibroma has a predilection for females with ignorance of age $[15,24$, 27-29]. The difference may be caused by the onset time. Our result suggested that for ossifying fibroma, onset time in females was a little later than males. This may explain why males were the majority of patients in children, whilst in adults females were more common.

Our results also demonstrate that ossifying fibroma in the jaws of children could be relapse and the recurrence rate is significantly associated with surgical methods and x-ray boundary features, but has no relation with gender, age, jaws, and pathological subtypes.

Comparing with many previously published reports, the total recurrence rate of ossifying fibroma in the jaws is higher in this report [2-4, 18, 20,27]. Differences of recurrence rates among different studies may be caused by many reasons. First of all, patient ages were different in different studies. The object of our study was patients below 18 years, but adults were included in many other reports [2-4, 18, 27], which also demonstrate that ossifying fibroma is more prone to children than adults. Besides, the inclusion criteria were different. In this study, cases with clinical, radiological, and pathological features that resembled the characteristics of ossifying fibroma were included, but in some reports, the inclusion criterion was with histopathological diagnosis of ossifying fibroma. It's not appropriate because diagnosis of ossifying fibroma should be a combination of clinical, radiological and pathological features. Moreover, the definitions of surgical strategies were not consistent. Many terms of surgery have been mentioned, such as enucleation, curettage, resection, local surgical excision, radical resection. Classification methods were different, and one term may have different meanings in different studies. For example, curettage in the study by Fadi et al. [3] was defined as excision from the surrounding normal bone, the areas underwent curettage were wider than those in our study. Lastly, preferences of surgeon may influence the choice of surgical approach. In only a few reports the cases were operated by one surgeon. Most of the reports the surgeons were not mentioned and may not the same one. For different surgeon the main consideration may be different. For example, main consideration for radical resection could be the border of the lesion [4], cortical perforation [30], enlargement rate, or size of the lesion [18]. Surgeon may tend to be conservative, considering the growth and development of the children.

Like many other tumors, there are many possible causes of tumor recurrence, such as a residue of the tumor tissue, the aggressive nature of the tumor, growth and development potential of children, treatment etc. Of course, the residue of the tumor tissue is the most common reasons and easily caused by the curettage. In some cases, the locations of the anatomic structures of the ossifying fibroma are complex, making it difficult to remove all the tumor tissue. Therefore, some surgeons might consider protecting important anatomic structures or saving function, resulting in some residues in these structures. A locally aggressive growth pattern may present as a poorly defined border on radiographs, so lesions with pool-defined boundary are easy to recur [23]. These findings indicated that radical resection could be used to avoid relapse. After radical surgery, reconstruction can be applied. Free flap grafting has gradually been shown to improve the growth of the issues in children [31-35].

In conclusion, ossifying fibroma showed a male predominance in patients below the age of 18 years. Recurrence rates were significantly associated with X-ray boundaries and surgical methods, but showed no relation with gender, age, jaws, and pathological subtypes in this study. Curettage had the highest relapse risk, whereas radical excision was the best strategy to avoid relapse. Extended resection and reconstruction with free tissue flap was a reliable method.

\section{Acknowledgements}

We thank prof. Yan Gao and Yan Chen (Department of Pathology, Peking University School and Hospital of Stomatology) and Zhi-Peng Sun (Department of Radiology, Peking University School and Hospital of Stomatology) for their constructive suggestions and helps in the study. This study was supported by the National Natural Science Foundation of China (Grant No. 81371162, 81100762 and 81671007).

\section{Author contribution}

All authors contributed significantly to this work. Z.-G.C. proposed, designed and revised the article. S.X. designed, summarized data and revised this article. Y.L. collected articles, summarized data, did statistical work and drafted the manuscript. X.-F.S. and X.-S.G. collected articles and summarized information in part. All authors reviewed this 
manuscript and approved the final draft.

\section{Competing Interests}

The authors have declared that no competing interest exists.

\section{References}

1. Neville BW, Damm DD, Allen CM, et al. Oral and Maxillofacial Pathology. St-Louis, USA: Saunders; 2012

2. Triantafillidou $K$, Venetis $G$, Karakinaris $G$, et al. Ossifying fibroma of the jaws: a clinical study of 14 cases and review of the literature. Oral Surg Oral Med Oral Pathol Oral Radiol. 2012; 114: 193-9.

3. Titinchi F, Morkel J. Ossifying Fibroma: Analysis of Treatment Methods and Recurrence Patterns. J Oral Maxillofac Surg. 2016; 74: 2409-19.

4. Mohanty S, Gupta S, Kumar P, et al. Retrospective Analysis of Ossifying Fibroma of Jaw Bones Over a Period of 10 Years with Literature Review. J Maxillofac Oral Surg. 2014; 13: 560-7.

5. Abramowicz S, Goldwaser BR, Troulis MJ, et al. Primary jaw tumors in children. J Oral Maxillofac Surg. 2013; 71: 47-52.

6. Troulis MJ, Williams WB, Kaban LB. Staged protocol for resection, skeletal reconstruction, and oral rehabilitation of children with jaw tumors. J Oral Maxillofac Surg. 2004; 62: 335-43.

7. Sun G, Chen X, Tang E, et al. Juvenile ossifying fibroma of the maxilla. Int J Oral Maxillofac Surg. 2007; 36: 82-5.

8. Harris MS, Vernon DJ, Agostino MA. An infant with right eye proptosis. Juvenile psammomatoid ossifying fibroma (JPOF). JAMA Otolaryngol Head Neck Surg. 2014; 140: 471-2.

9. Williams HK, Mangham C, Speight PM. Juvenile ossifying fibroma. An analysis of eight cases and a comparison with other fibro-osseous lesions. J Oral Pathol Med. 2000; 29: 13-8.

10. Wang $H$, Sun $X$, Liu $Q$, et al. Endoscopic resection of sinonasal ossifying fibroma: 31 cases report at an institution. Eur Arch Otorhinolaryngol. 2014; 271: $2975-82$.

11. Lee YB, Kim NK, Kim JY, et al. Low-grade osteosarcoma arising from cemento-ossifying fibroma: a case report. J Korean Assoc Oral Maxillofac Surg. 2015; 41: 48-51.

12. Smith SF, Newman L, Walker DM, et al. Juvenile aggressive psammomatoid ossifying fibroma: an interesting, challenging, and unusual case report and review of the literature. J Oral Maxillofac Surg. 2009; 67: 200-6.

13. Dominguete PR, Meyer TN, Alves FA, et al. Juvenile ossifying fibroma of the jaw. Br J Oral Maxillofac Surg. 2008; 46: 480-1.

14. Hakeem AH, Hakeem IH. Juvenile ossifying fibroma of paranasal sinuses-do we need to be radical in surgery? J Craniofac Surg. 2013; 24: e257-8.

15. Young N, Rowson JE. Cementifying fibroma of the frontal bone: a case report. Br J Oral Maxillofac Surg. 2007; 45: 667-9.

16. Thakur G, Nair PP, Ahuja R, et al. Juvenile ossifying fibroma of the maxilla. BMJ Case Rep. 2011; 2011: 3896.

17. Marvel JB MM, Catlin FI. Ossifying fibroma of the midface and paranasal sinuses: diagnostic and therapeutic considerations. Otolaryngol Head Neck Surg. 1991; 104: 803-8.

18. Lv M, Shen Y, Li J, et al. Which Patients With Ossifying Fibroma of the Jaws Would Be Suitable for Radical Ablative Surgery? J Craniofac Surg. 2016; 27: 927-31.

19. Colmenero-Ruiz C, Cano-Sanchez J, Lopez-Arcas JM, et al. Multistage reconstruction in facial juvenile psammomatoid ossifying fibroma: clinical therapeutic conference. J Oral Maxillofac Surg. 2011; 69: 2055-63.

20. MacDonald-Jankowski DS. Ossifying fibroma: a systematic review. Dentomaxillofac Radiol. 2009; 38: 495-513.

21. Norman JS. Nelson Textbook of Pediatrics. Philadephia, USA: Elsevier; 2004.

22. Assembly UNG. Convention on the Rights of the Child, 20 November 1989. Annu Rev Popul Law. 1989; 16:485-501.

23. Slootweg PJ, Muller H. Differential diagnosis of fibro-osseous jaw lesions. A histological investigation on 30 cases. J Craniomaxillofac Surg. 1990; 18: 210-4.

24. Phattarataratip E, Pholjaroen C, Tiranon P. A Clinicopathologic Analysis of 207 Cases of Benign Fibro-Osseous Lesions of the Jaws. Int J Surg Pathol. 2014; 22: 326-33.

25. Barnes L, Everson JW, Reichart P. Pathology and Genetics: Head and neck tumors. Lyon, France: IARC Press; 2005.

26. Rinaggio J, Land M, Cleveland DB. Juvenile ossifying fibroma of the mandible. J Pediatr Surg. 2003; 38: 648-50.

27. Urs $\mathrm{AB}, \mathrm{Kumar} \mathrm{P}$, Arora $\mathrm{S}$, et al. Clinicopathologic and radiologic correlation of ossifying fibroma and juvenile ossifying fibroma--an institutional study of 22 cases. Ann Diagn Pathol. 2013; 17: 198-203.

28. da Silveira DT, Cardoso FO, BJ ES, et al. Ossifying fibroma: report on a clinical case, with the imaging and histopathological diagnosis made and treatment administered. Rev Bras Ortop. 2016; 51: 100-4.

29. Yang BT, Wang YZ, Wang XY, et al. Imaging study of ossifying fibroma with associated aneurysmal bone cyst in the paranasal sinus. Eur J Radiol. 2012; 81: $3450-5$
30. Costa $\mathrm{H}$, Zenha $\mathrm{H}$, Sequeira $\mathrm{H}$, et al. Microsurgical reconstruction of the maxilla: Algorithm and concepts. J Plast Reconstr Aesthet Surg. 2015; 68: e89-e104.

31. Espinosa SA, Villanueva J, Hampel $\mathrm{H}$, et al. Spontaneous regeneration after juvenile ossifying fibroma resection: a case report. Oral Surg Oral Med Oral Pathol Oral Radiol Endod. 2006; 102: e32-5.

32. Converse JM, Coccaro PJ, Valauri AJ. Resection of a giant ossifying fibroma through an intraoral approach in a 9-year-old child: immediate reconstruction and 6-year cephalometric follow-up. Plast Reconstr Surg. 1982; 69: 511-20.

33. Guzel MZ, Arslan H, Sarac M. Mandibular condyle reconstruction with inlay application of autogenous costochondral graft after condylectomy: Cerrahpasa's technique. J Oral Maxillofac Surg. 2007; 65: 615-20.

34. Zhang WB, Liang T, Peng X. Mandibular growth after paediatric mandibular reconstruction with the vascularized free fibula flap: a systematic review. Int J Oral Maxillofac Surg. 2016; 45: 440-7.

35. Salyer KE, Barcelo CR, Por YC. Extensive neglected psammomatoid ossifying fibroma with craniofacial deformity. J Craniofac Surg. 2004; 15: 1033-9. 